\title{
Febrile morbidity post laparoscopic myomectomy for symptomatic large submucous myoma in an adolescent girl
}

\author{
Prabha Agrawal $^{1 *}$, Rahul Agrawal ${ }^{2}$, Sri Varshini Muthineni ${ }^{1}$
}

${ }^{1}$ Department of Obstetrics and Gynecology, ${ }^{2}$ Department of Internal Medicine Medicover Hospital, Hyderabad, Telangana, India

Received: 27 July 2021

Accepted: 27 August 2021

\section{*Correspondence:}

Dr. Prabha Agrawal,

E-mail: drprabha1001@yahoo.com

Copyright: (c) the author(s), publisher and licensee Medip Academy. This is an open-access article distributed under the terms of the Creative Commons Attribution Non-Commercial License, which permits unrestricted non-commercial use, distribution, and reproduction in any medium, provided the original work is properly cited.

\begin{abstract}
The occurrence of post-operative fever after myomectomy without an apparent infectious cause has been reported in various studies. We here in report a case of an 18-year girl with abnormal uterine bleeding and severe anemia resulting from a large $5 \mathrm{~cm}$ submucosal fibroid. She underwent laparoscopic myomectomy. Surgery was uneventful. Postoperative she had fever of $100.4^{\circ} \mathrm{F}$ which lasted for 48 hours. Antibiotic coverage was continued for 48 hours. Her urine culture and hemogram were negative for infection. Early postoperative fever is most commonly caused by inflammatory changes rather than infectious causes. Large submucous fibroids can be managed by laparoscopy with excellent clinical outcomes and minimal morbidity.
\end{abstract}

Keywords: Adolescent, Submucous myomas, Laparoscopic myomectomy, Post-operative fever

\section{INTRODUCTION}

Uterine leiomyomas are the most common benign gynecological tumor in the reproductive year with a prevalence of $20-40 \%$ in women over the age of 35 years. ${ }^{1}$ However, their occurrence in the adolescent population is extremely rare $(<1 \%)$, with few reports documented in the literature. $^{2}$

There are no treatment guidelines for symptomatic fibroids in adolescents. ${ }^{3}$ Myomectomy, although invasive, is probably the most adequate treatment owing to the low recurrence rates of fibroids, preserves fertility, and doesn't interfere with the hormonal milieu of the developing teenager. ${ }^{2}$ Hysteroscopic myomectomy is considered the first-line conservative surgical therapy for the management of symptomatic submucous fibroids. To avoid complications of hysteroscopy, laparoscopic removal of large submucous myomas can be done. ${ }^{1}$

The removal of fibroids penetrating the uterine cavity by laparoscopy is of concern because of the risk of intra- and post-operative bleeding and opening the cavity could theoretically increase the risk of uterine and pelvic infection. $^{4}$

The existence of post-operative myomectomy-specific fever without an apparent infectious etiology, can be found cited in review articles, but there are no published data to support the existence of this clinical entity. ${ }^{5}$ Explanations for these fevers vary from intra-myometrial hematoma formation to the release of unspecified factors from the myoma during its dissection. ${ }^{5}$

\section{CASE REPORT}

An 18-year girl came with complaints of menorrhagia for 6 months with dysmenorrhea. She had history of anemia (Hb $6.7 \mathrm{gm} \%$ ) for which two blood transfusions were given 1 month back. She was on oral progesterone and tranexamic acid for 6 months. Her ultrasound showed enlarged uterus with a $5.0 \times 3.6 \mathrm{~cm}$ sub-mucus myoma 
occupying whole of uterine cavity. After detailed counselling and informed consent she was posted for laparoscopic myomectomy. She underwent basic blood investigations and was found to have $\mathrm{Hb}$ of 10.9 gram $\%$. After admission subcutaneous low-dose heparin injection $40 \mathrm{mg}$ was given 12 hours before surgery. Antibiotic prophylaxis was given 1 hour before surgery (Injection ceftriaxone 1 gram IV).

The surgery was performed under general anesthesia. With the patient in modified lithotomy position a $10-\mathrm{mm}$ port was inserted supraumbilically with three 5-mm accessory ports.

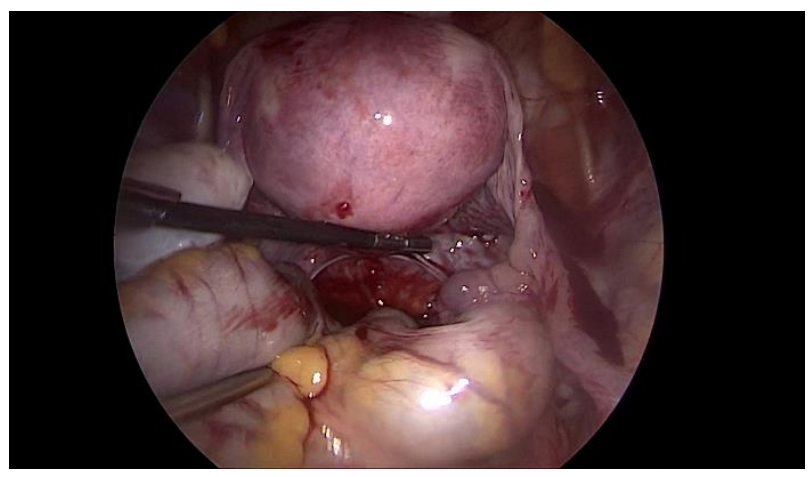

Figure 1: Laparoscopic view of uniformly enlarged uterus of 10 weeks size.

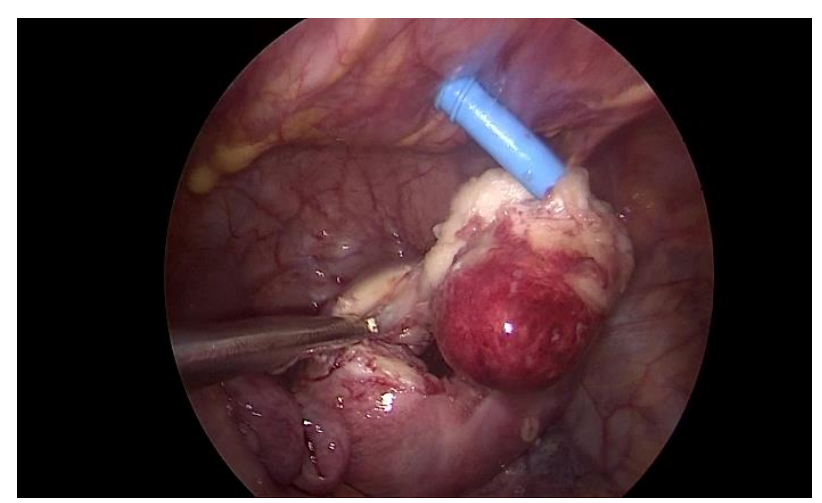

Figure 2: Laparoscopic view of submucus myoma with a breached endometrial cavity.

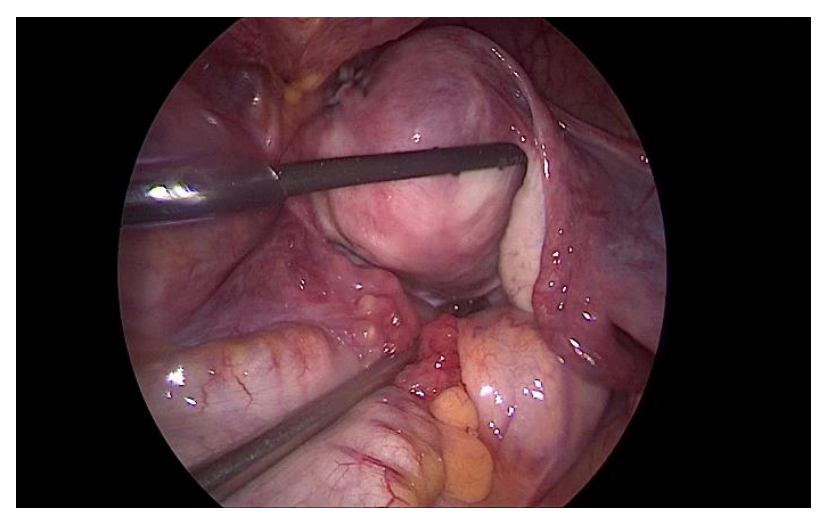

Figure 3: Laparoscopic view of sutured uterus.
At laparoscopy, the uterus was uniformly enlarged to 10 weeks size with healthy adnexa (Figure 1). 2 cc solution of vasopressin diluted in $100 \mathrm{ml}$ saline was injected into the tissue layers to make tissues ischemic and to delineate the cleavage plane. An oblique incision was given on the fundus of the uterus using a monopolar scalpel. The incision was widened and deepened until the pseudocapsule was reached. A 5-mm myoma spiral was used to enucleate the myoma by gentle traction and countertraction (Figure 2). Endometrial cavity was opened incidentally but was reposited back. Myometrial bed was sutured in two layers with barbed suture (V-Lok) at $1 \mathrm{~cm}$ increments not including the endometrial lining (Figure 3). The enucleated myoma was then retrieved by contained electromechanical morcellation in endo-bag through supraumbilical port. After a thorough laparoscopic check, peritoneal cleansing and haemostasis adhesion barrier (intercede) was placed on the suture line. A drain to observe possible intraabdominal bleeding was placed. Ports were closed with 3-0 delayed absorbable subcuticular sutures. The urinary catheter was removed after 6 hours. Patient was started on liquid diet 6 hours post surgery. Total operating time was 75 minutes with intrasurgical blood loss of $100 \mathrm{ml}$. Post-surgical serosangoinous $50 \mathrm{ml}$ output in drain was noted. Postoperative patient had fever of $100.4^{\circ} \mathrm{F}$ noticed after 6 hours which continued for 48 hours $\left[\leq 100.4^{\circ} \mathrm{F}\right]$. She had mild tachycardia with normal CVS, RS and per abdomen findings. There was no IV canula site thrombosis. Drain was removed $24 \mathrm{~h}$ post-surgery. Antibiotic given preoperatively was continued in view of persistent postoperative pyrexia for 48 hours. Hemogram sent after 24 hours showed TLC [8500], DLC [N-76, L-20, E-2, B-0, $\mathrm{M}-2]$. ESR was $22 \mathrm{mmHg}$ and urine culture were negative. Intra-myometrial hematoma was ruled out by ultrasound abdomen and pelvis. The suspected source of the fever could not be traced. Fever subsided after 48 hours and the patient was discharged after 24 hours of last fever spike. On 1 week follow up she was afebrile. Histopathological examination showed benign leiomyoma with weight of $200 \mathrm{gm}$.

\section{DISCUSSION}

The observation of symptomatic uterine fibroids among pediatric and adolescent population is an uncommon event. The first reported case was made by Wisot et al in 1969 , in which a 15-year-old girl underwent abdominal myomectomy and there was a recurrence of the lesion six months after surgery. ${ }^{2}$

Treatment of women with uterine leiomyomas must be individualized based on patient's age, symptomatology, tumour size, location and need to preserve fertility. Semm and Mettler published their first paper on laparoscopy myomectomy in $1980 .{ }^{6}$ Today, all myomas can be enucleated by this technique. Hysteroscopic myomectomy is not advisable if the sub-mucus myoma is larger than 5 or $6 \mathrm{~cm}$, if more than $50 \%$ of the endometrial surface is affected by myoma size or number, or if the size of the 
uterine cavity has been limited to that of 16 weeks of gestation. $^{1}$

Fever is any body temperature above $>37.2^{\circ} \mathrm{C}\left(>98.9^{\circ} \mathrm{F}\right)$ in morning and $>37.7^{\circ} \mathrm{C}\left(>99.9^{\circ} \mathrm{F}\right)$ in evening. In practice temperature above $100.4^{\circ} \mathrm{F}\left(38^{\circ} \mathrm{C}\right)$ is considered as significant. The causes of post-procedural fever range from inflammation or drug reaction to life threatening necrotizing soft-tissue infection (NSTI). ${ }^{7}$ Classic "Ws" of post-operative fever are atelectasis (pod 1-2), urinary tract infection (pod 2-3), wound infection (pod 3-7), deep vein thrombosis/thrombophlebitis (pod 5-7) and drug fever $(\operatorname{pod}>7){ }^{7}$

Transient episodes of febrile morbidity, without an increase in the inflammatory index are most commonly attributed to noninfectious causes. Fever presenting later than 48 hours after surgery and temperatures more than $102^{\circ} \mathrm{F}$ raise concern for an infectious cause. ${ }^{7}$ In a study of 81 patients with idiopathic postoperative fever, Garibaldi et al found that $80 \%$ of those with fever on the first postoperative day had no infection. ${ }^{7}$ Dellinger showed that early fevers (between days 1 and 4) rarely represent an infection. $^{7}$

Immediate postoperative fever is most commonly caused by inflammatory changes from the release of pyrogenic cytokines, primarily interleukin (IL)-1, IL-6, tumor necrosis factor, and interferon-G. ${ }^{7}$ Dissection of the myoma from the surrounding myometrium could transiently release pyretic factors. ${ }^{5}$ The amount of tissue trauma seems to have a causal relationship with the release of IL- 6 and thus to the development of fever. ${ }^{7}$ Newton et al suggested a possibility of pyretic response to the reabsorption of the extra blood left in the peritoneal cavity. $^{5}$

In a study by Ronald et al among patients who underwent myomectomy, $67 \%$ had no source recorded, $27 \%$ had atelectasis, $2 \%$ had "myomectomy-related fever," $2 \%$ had endometritis, and $2 \%$ had urinary tract infections. Only a small fraction $(3 \%-5 \%)$ had rigid documentation of their fever source by imaging study or culture. ${ }^{5}$

The use of prophylactic antibiotics, an adhesion barrier, vasopressin or entry into the uterine cavity did not significantly affect febrile morbidity. ${ }^{5}$ Iatrogenic infusion of IV fluid contaminated by microbial infection can be a reason for postoperative chills.

Management strategies for patients with post-procedure fever should take into consideration the degree of fever and the timing of its onset.

\section{CONCLUSION}

For fibroids in the adolescent patient, the surgeon should select the optimal surgical approach with fertility preservation almost always a priority. Literature suggests that there is an increase in febrile morbidity in the immediate postoperative period that is specific to myomectomy and is mostly non-infectious. But still, it decreases patient satisfaction and increases the antibiotic usage. Routine laboratory studies, cultures, and radiographic imaging should all be tailored to individual cases. Antibiotics should be administered promptly as an adjunct to source control. A clear understanding of the timing of the onset of fever in relation to the operation can differentiate likely diagnoses.

Funding: No funding sources

Conflict of interest: None declared

Ethical approval: Not required

\section{REFERENCES}

1. Sinha R, Sundaram M, Mahajan C. Laparoscopic removal of large submucous myomas. Gynecol Surg. 2012;9:37-41.

2. Moroni RM, Vieira CS, Ferriani RA. Presentation and treatment of uterine leiomyoma in adolescence: a systematic review. BMC Womens Health. 2015;15:4.

3. Ernest A, Mwakalebela A, Mpondo BC. Uterine leiomyoma in a 19-year-old girl: Case report and literature review. Malawi Med J. 2016;28(1):31-3.

4. Seracchioli R, Colombo FM, Bagnoli A. Laparoscopic myomectomy for fibroids penetrating the uterine cavity: is it a safe procedure? BJOG: an Int J Obstetr Gynaecol. 2003;110:236-40.

5. Iverson RE Jr, Chelmow D, Strohbehn K. Myomectomy fever: testing the dogma. Myomectomy. 1999;72(1):104-8.

6. Mettler L, Schollmeyer T, Tinelli A. Complications of Uterine Fibroids and Their Management, Surgical Management of Fibroids, Laparoscopy and Hysteroscopy versus Hysterectomy, Haemorrhage, Adhesions, and Complications. Obstetrics and Gynecology Int. 2012;791248.

7. Narayan M, Medinilla SP. Fever in the Post-operative patient. Emerg Med Clin North Am. 2013;31(4):104558.

Cite this article as: Agrawal $\mathrm{P}$, Agrawal $\mathrm{R}$, Muthineni SV. Febrile morbidity post laparoscopic myomectomy for symptomatic large submucous myoma in an adolescent girl. Int J Reprod Contracept Obstet Gynecol 2021;10:3970-2. 